\title{
Speaking Characters in Selected Novels of Bharati Mukherjee
}

\author{
Dolly Sharma $^{1} \&$ Jaya Dwivedi ${ }^{2}$
}

${ }^{1}$ Assistant Professor, Parthivi College of Engg. E Mgmt. Bhilai, C.G, India and Research Scholar in the Department of English at N.I.T Raipur, C.G, India. Email: dollyjayamzo16@gmail.com.

${ }^{2}$ Jaya Dwivedi is Assistant Professor in the Department of English at N.I.T, Raipur, C.G, India. Email: jdwivedi.eng@nitrr.ac.in.

Received April 19, 2016; Revised July 04, 2016; Accepted July 15, 2016; Published August 18, 2016

\begin{abstract}
The Feminist Theory of Situated Knowers justifies the accounts of women by allowing them to depict their plight and contribute to epistemology by speaking from a position which they have experienced. The protagonists in selected novels of Bharti Mukherjee speak for themselves setting a ground to be examined under the example of Situated Knowers Theory in this paper. These protagonists highlight the gendered and ethnically underlined identities of women especially Indian women. The protagonists Tara Banerjee, Jasmine, Dimple and Tara Bhattacharya of selected novels The Tiger's Daughter, Jasmine, Wife and Desirable Daughters face varied situations as women and immigrants to find a sense of self in the new world .They undergo struggle to shed the tangles of the complex expectations and chains of conventions to be themselves. Bharti Mukherjee's selected women characters are strong, defy conservative norms, stay true to the spirits of exploration, learn the secret of survival and make a place for them in a world that seems to conspire against them.
\end{abstract}

Keywords: Situated Knowers, epistemology, standpoint theory, gendered identities, Self-exploration

\section{Introduction}

Bharati Mukherjee raises a feminist voice through the speaking women characters of her novels sharing their complications of gender inequality and strictly defined gendered identity. Mukherjee, an Indian writer married a man from Canada deviating from Indian tradition, has an in-depth and distinctive approach towards feminism because of her Indian background and American migration. The characters of Bharati Mukherjee make an emphatic statement about the gendered and ethnically defined identities of women, especially Indian women, how they have to go through a substantial amount of hardships and struggle to shed the tangles of the complex expectations and chains of conventions to be themselves to lead their lives the way they aspire to live .Some of the selected novels of Bharati Mukherjee that are the subject of this paper include The Tiger's Daughter, Desirable Daughters, Jasmine and Wife.

These novels highlight the suffering of their female protagonists, their journey of becoming self-dependent and creating identities of their own on their own terms. The feminist theory that can be applied to the speaking characters of Bharati Mukherjee is Situated Knowers Theory as Bharati Mukherjee is making a statement about her own experiences and observations on the issues faced as a woman in traditional Indian and foreign country by the medium of her

(c) AesthetixMS 2016. This Open Access article is published under a Creative Commons Attribution Non-Commercial 4.0 International License (http://creativecommons.org/licenses/by-nc/4.o/), which permits non-commercial re-use, distribution, and reproduction in any medium, provided the original work is properly cited. For citation use the DOI. For commercial re-use, please contact editor@rupkatha.com. 
female characters. They include Tara Banerjee in The Tiger's Daughter, three sisters Padma, Parvati and Tara in Desirable Daughters', Jyoti in Jasmine and Dimple in Wife.

The characters of Bharati Mukherjee tell tales of gender, racial and ethnic complications shedding light on the challenges faced by immigrants but the focus of this paper is the feminist aspect of her work and the application of the Situated Knowers Theory to her novels and characters. Furthermore, as Situated Knowers, the characters of Mukherjee have knowledge regarding the social repression and extreme conditions faced by women but they acquire the status of "survivors", rising from the ashes of emotional and corporal form of challenges (Myles 107). Bharati Mukherjee helps her characters to evolve their identity but her female characters gain more spotlight than her male characters because the stories are more about the struggle and subsequent success of women in their identities.

\section{The Shades of Feminism}

The female protagonists of Bharati Mukherjee have to face several challenges to find their sense of identity and self within the perimeters of a huge society. The women in these novels have an innate desire and propensity to engage in the act of exploration finding new horizons instead of being crippled by their circumstances despite being subjected to extreme amounts of scrutiny. The women in these novels come to the U.S. with their aspirations, face a huge number of challenges, find an emerging identity and also transform the look of America (Myles 108). Therefore these women serve as instances of the heroic aspects of feminism.

Further, the female characters of Bharati Mukherjee are a reflection of her own identity and struggle as someone from India who left India, went to Canada facing challenges while settling in the U.S. The different stages of Mukherjee's life are evident from the transformation and progression of her characters since the latter make a statement about the unfolding identity of Mukherjee herself. The women in Mukherjee's novels react physically, intellectually and emotionally to a variety of situations, along with the other characters that are out of their comfort zone. The characters in the aforementioned novels make an emphatic statement that brutality goes beyond corporal violence as psychic forms of brutality may be severer, more extreme and impactful than corporal violence. Women usually have to face a lot of such pressure and while some may succumb to the pressure, Mukherjee's heroines find a way and emerge stronger. All these facets also underline the role of Mukherjee and her characters as Situated Knowers.

Women in general may not always be subjected to domestic violence or violence in other forms but the most complicated form of violence they have to go through is psychological. Indian women and women in many parts of the world have to go through gender discrimination and are expected to adhere to closely defined gender and societal roles. The expectations from women in these cases are sacrifices choking their desires and serving others without raising a single objection. Women in Bharati Mukherjee's work also have to go through several challenges but they have an undying spirit and capitalize on whatever they have to make their lives and existences more substantial.

In addition, the women in the novels of Bharati Mukherjee have to face "double colonization", including those originating from both "patriarchy" and "expatriation" (Gupta 2). This also makes a statement about the characters of Mukherjee as Situated Knowers. Bharati Mukherjee's Indian birth accentuates that she has observed and noted the limitations and "atrocities" that Indian women are subjected in society. (Gupta 2). 


\section{The Feminist Theory of Situated Knowers}

The work and characters of Bharati Mukherjee can be analyzed in light of the feminist theory pertaining to "Situated Knowers". The gender of a person leaves an effect on the knowledge of different things and a significant number of other factors. The feminist theory of Situated Knowers underlines the significance of comprehending the plight of a group of people or more specifically women from a position in which they might have had a chance to experience obstacles or extreme emotions or pressure in a situation reacting to it strongly as women. The feminist theory of Situated Knowers further accentuates that the historical status of knowers including their profile, "emotions, relationships with others, and social status", leaves an impact on the availability of knowledge to them and the manner in which they make their pronouncement or declaration of knowledge in the form of displaying, validating and embracing it as dominant (Gardner 77). In other words, women experience the kind of obstacles and issues that are specific to their gender and men may not have proper knowledge because they don't go through the same. Further, in accord with the Feminist Theory the impact of the historical profile and other details surrounding Situated Knowers does not face a requirement to be comprehended as unfavorable because the emotional reaction of a situated knower may actually increase the chance of 'epistemic privilege' because the situated knower is aware of something special, has experienced what others have not and contributed exact wisdom regarding a specific topic.

Even, in accord with Feminist Standpoint Theory one can infer that unless the social status of women is improved that is treating on par with men; any talk of feminist liberty will be churlish. To define it more specifically, women need to be treated equally not only socially but also psychologically. Iris Young has provided a similar understanding of femaleness, stating that

"I take 'feminity' to designate not a mysterious quality or essence that all women have by the virtue of being biologically female. It is rather, a set of structures and conditions that delimit the typical situation of being a woman in a particular society, as well as the typical way which this situation is lived by women themselves." (1990, 143-4)

In other words, by assigning a considerable amount of importance to Situated Knowers, feminist epistemologists challenge the aims of conventional epistemology because the latter pertains to an overall approach to knowledge that stems from "abstract" and disconnected knowers (Gardner 77).

Moreover, in accord with feminist theory, assessing the situation of the knower indicates a "patriarchal, sexist and misogynist" element leaving an effect on various understandings (O'Donohue). The concept of embodiment becomes important here because in light of this concept, people experience different happenings through the medium of their bodies and react in unique ways. Those who approach a subject from the front will be of a different perspective than those having a bird's eye view. (O'Donohue)

\section{Application of the Theory to Bharati Mukherjee's Works}

When the feminist theory of Situated Knowers is applied to the selected novels of Bharati Mukherjee, it indicates a perspective on the issues faced by women in India and after migrating to America. Further, different works of Bharati Mukherjee depict the progression of their characters and the reconstruction of their identities in specific ways. On the surface, the novels and characters of Bharati Mukherjee may seem to be about the plight of immigrants but her women go through the hardships they face and a need for reaffirming their identity because of their 
gender they have to encounter impediments and conflicts in their gender and individual roles (Babu and Kumar 40). In addition, Bharati Mukherjee also engages in the act of giving rise to an equation between the two genders in such a manner that women can enjoy an equivalent status as men and the two genders can interact based on an understanding that is not governed by "oppression" or "exploitation" (Babu and Kumar 40). The novels of Bharati Mukherjee act as a reflection of the progression of Indian society because men are no longer the nucleus of the gravitation of women in many cases and this is evident from understanding the perspective of a Situated Knower.

The Tiger's Daughter originates from the perspective of a Situated Knower depicting the struggles of an Indian woman in western society trying to create a new identity for herself making her nostalgic about her Indian roots. The novel also reflects Mukherjee's own story of marrying a Canadian man in the form of the protagonist Tara's marriage to an American and substantiates her role as a Situated Knower. Additionally, Tara's role is a classic depiction of a feminist tale on the complexities faced by women. Since Tara marries an American Jew, she has to meet the disapproval of her parents and society who expect her to live by the standards, expectations and definitions set by them. Further, by marrying someone from the outside world and traveling back to India alone without her husband, Tara has broken the invisible chains that bind her to stay true to others' mindset. Others in India react with shock and doubt Tara's visit to India without her husband making clear the set of expectations and requirements that women have to stay true to in Indian society. As depicted in a passage from The Tiger's Daughter, "Perhaps her mother sitting severely before God on a tiny rug, no longer loved her either. After all Tara had willfully abandoned her caste by marrying a foreigner" (Mukherjee, The Tiger's Daughter 50). This passage depicts the severity of the plight faced by Tara in the role of a Situated Knower. Only a Situated Knower may be aware of the alarming nature of matters when someone as full of love as a mother may seem to stop loving a daughter when the daughter has defied tradition.

Further, the character of Tara in The Tiger's Daughter experiences the kind of loneliness that can only come from facing a complex array of difficulties as a woman and expatriate, the theory of Situated Knowers helps to understand the concept in a much better way. At one point, Mukherjee describes Tara's ordeal by underlining the torment she feels as if "each atom of newness bombarded her" (The Tiger's Daughter 13). Tara is at the heart of a situation which she may not have faced if she were not a woman and therefore, her position as a Situated Knower becomes clear in this context. Men usually do not have to change their own identity while women are usually expected for it. Tara's arc of life and social location justify her position as a Situated Knower because she is qualified to demonstrate the issues faced by women in India. While those in India who are quick to judge Tara may believe that they know everything and have the authority to comment on Tara's situation, they cannot possibly claim to know her struggles and her rising emptiness. It is only Tara who is aware of the challenge of her situation. When Tara Banerji goes back to India alone, the severity of the reaction of her relatives can only be properly comprehended by a Situated Knowers. Indian conventions underline a requirement for a male to dominate, direct, shield a woman and guide her path but when Tara returns alone to India breaking this tradition, her entire existence is under scrutiny. Mukherjee's role as a Situated Knower also blooms in this context because she returned to India from America at some point and faced resistance. The hostility that Tara finds herself on the receiving end can further be understood by a Situated Knowers only because she has breached the rules of society and chosen to marry someone who is not even from their country, religion or caste. 
Mukherjee's 'Jasmine' also depicts the plight and challenges faced by Jasmine and underscore her position as a Situated Knower. In the works of Bharati Mukherjee, gender has diversity and may transform based on "place, time and situation" (Dubey and Srivastava 161). In Jasmine, Jasmine's journey and change of identity documents the extreme nature of struggles women have to go through because of their gender and the resulting confusion and complexities they face as Situated Knowers in this context. Jasmine "sheds lives" to acquire new roles and as the story progresses, she moves away from her conservative Indian past, more specifically "Lahori Jat peasant" roots, to adjust to the western world and evolve in a new fashion (Srivastava). The change of names "Jyoti-Jasmine-Jazzy-Jase-Jane-Jasmine" mirrors the development of Jasmine's character and its evolving strength (Srivastava 2). These changing names highlight the different levels of her journey as a Situated Knower featuring a woman's struggles in unfavorable surroundings.

Mukherjee further demonstrates her females in their roles as Situated Knowers to break the patriarchal chains of a conventional society and how they are liberated and empowered (Dubey and Srivastava 160). This also adds weight to Mukherjee and her characters' position as situated knowers because of their past. "Lifetimes ago, under a banyan tree in the village of Hasnapur, an astrologer cupped his ears -- his satellite dish to the star -- and foretold my widowhood and exile. I was only seven then" (Mukherjee, Jasmine). Jyoti or Jasmine has to listen to the prediction about her widowhood when she is just seven and an innocent child, which shows how the targeting of women and their introduction to bitterness starts at an early age, and how they acquire the status of Situated Knowers. Jyoti, who belonged to a poor village household in India, has to give rise to new identities to survive and emerge as a combatant. Jyoti refuses to marry a Hindu based on horoscopes, which is an intrinsically old tradition in India and marries a Christian husband named Prakash to assume the identity of Jasmine. The enormity of her decision to deny the significance of caste, religion and horoscopes in the context of marriage and the courage behind it can only be presented and understood by a Situated Knower.

After marrying a Christian, Jyoti becomes Jasmine symbolizing the transformation a woman as a situated knower, goes through in the Indian society after marriage. In India, the identity of a woman as an individual usually ceases to exist after marriage. When the life of her husband comes to an early end, Jyoti/Jasmine has to bear the brunt of the judgment of her nearest relatives who believe that she angered God by deviating from traditions becoming a widow at an early age breaking the tradition of relying on horoscopes. This also reasserts the position of Bharati Mukherjee as a situated knower because she understands how the mindsets of conventional people work in this context and how they may arrive with their judgment the moment something bad happens, especially to a woman, because they cannot believe that she dared deviate from tradition. At one point, when Jasmine thinks about her partner Bud, she reflects, "I think sometimes I saved his life by not marrying him" (Mukherjee, Jasmine). This highlights the position of Jasmine as a Situated Knower because she has been a victim of the oppression and ruthlessness of society and sometimes, even though partly in jest, even blames her for the things society blames her for.

Further, by making a decision to migrate to America after becoming a widow and refusing to be subjected to what widows have to go through in a conventional Indian society, Jasmine emerges as a face for feminism as a Situated Knower because she makes her own choices and dictates her terms of living instead of succumbing to tradition. Jasmine is raped on the ship that takes her to America and her decision to commit suicide also comes from the perspective of a Situated Knower. Writers like Bharati Mukherjee can truly capture how hopeless an Indian 
widow may feel after being raped and the severity of hopelessness which may drive her to end her life. Mukherjee further makes an emphatic statement about feminism when Jasmine changes her mind and decides to live based on her spirit and love for life.

The role of Jasmine as a Situated Knower is also evident from other aspects of her journey. Jasmine's words after getting raped by Half-Face highlight, "I tried to keep my eyes on Ganapati and prayed for the strength to survive, long enough to kill myself" (Mukherjee, Jasmine 116). This also accentuates Jasmine's position as a Situated Knower because she has been in a position where she faced one of the most humiliating and demoralizing injustice a woman can go through and wanted to kill herself because of it. Her emergence as a strong feminist becomes more pronounced when she decides to kill her rapist instead of herself. When Jasmine/Jyoti kills her rapist and acquires a new identity to learn and earn in America, she defies tradition and rises from the ashes to have a new kind of strength and power (Ramachandran and Bhat). In her quest to accomplish her dreams, Jasmine feels the need to kill herself (or her identity) to emerge as someone new and closely linked with her new home i.e. America (Erten 36). Jasmine's own experiences the tales she tells about others including an Indian girl Vimla who set herself to fire after her husband's death to join him accentuate her position as a Situated Knower because Jasmine's social location within different societal setups has allowed her to experience and observe the issues faced by women firsthand.

Furthermore, the story of Dimple in Bharati Mukherjee's Wife also originates from the perspective of a Situated Knower because a woman who has had to face the pressure, restrictions and sense of confinement of a conventional Indian home, especially in-laws, can comprehend the plight of Dimple. Bharati Mukherjee raises a voices for the feminist evolution of Dimple by recording her journey from the time when she had a habit of dreaming about marriage and being a wife but when Dimple actually became a wife, she started resenting her wifely duties, pressures, demands associated with it. She attempts to reassert her identity, away from her marriage, because she wants to be known for herself instead of just being a wife. Dimple's position as a Situated Knower is evident from the words of the novel. In accord with the syntax of 'Wife'"Marriage alone teaches the virtues of sacrifice, responsibility and patience" (Mukherjee, Wife 27). Also, "A cheating wife is not to be understood and sympathized with" (Mukherjee, Wife 27). These quotes from the novel 'Wife' make the position of Dimple clear as a Situated Knower because women placed in a certain situation can actually know the reality and ramifications surrounding the situation instead of those who have never been in that situation.

The above information pertains to the perspective of a Situated Knower because everybody cannot comprehend the frustrations that may be experienced by an Indian wife due to a huge number of expectations and responsibilities. Dimple attempts to reaffirm her identity by avoiding several of her duties as a wife and some include the fact that she induces a miscarriage to avoid the married duty of pregnancy. Since her mother-in-law and husband do not appreciate and try to oppress her, she falls in love with another man, Milt. He appreciates and values her with her traits. She ends up going against her husband and mother-in-law defying everything that was ever taught to her by tradition. Dimple's marriage is a façade because her husband tries to mock, insult and confines her in everything she does. When Dimple does not feel accepted and appreciated by her husband Amit and feels the need for change which cannot be supported by him, she bids adieu to her marriage to facilitate change. At one point, Dimple thinks about and sympathizes with another woman, "Who knows, this woman could, out of sheer despair, turn to worse things, like real sin" (Mukherjee, Wife 28). This line also adds credibility to the character of 
Dimple as a Situated Knower because not only she has experienced oppression herself, but she has also seen other women being subjected to it and is aware of the consequences.

The female protagonists of Desirable Daughters, Tara, Padma and Parvati, are a personification of the perspective of a Situated Knower. Mukherjee's novel Desirable Daughters also highlights another important tidbit shared by a Situated Knower because in conventional Indian society, daughters symbolize the honor of the family therefore, they are required to behave in a "desirable" manner or in other words, in harmony with the norms underlined by the society they dwell (Gupta 2). Daughters in India are supposed to stay true to a specific code of conduct and can only fulfill the definition of desirability by adhering to this. Another significant aspect of Desirable Daughters sheds light on the Indian tradition in which women are support to sacrifice what they want for the good and objectives of the community they live in. Women are supposed to please everyone around them. The narrator Tara Bhattacharjee tells the tale of her ancestor Tara Lata in the Desirable Daughters and signifies, "A Bengali girl's happiest night is about to become her lifetime imprisonment. It seems all the sorrows of history, all that is unjust in society and cruel in religion have settled on her" (Mukherjee, Desirable Daughters 4). This passage sheds light on the height of extremity faced by girls in traditional Indian society. Tara Lata is first going to be a child bride at five years of age but when her fiancé becomes a victim of a snake and eventually death on her wedding night, her father gets her married to a tree to save her from becoming a widow. At the tender age of five, she becomes a Tree-Bride and has to lead a colorless life from then onward, confined to the compound. Tara faces a marriage to a tree to get rid of the supposedly harmful possibilities of her horoscope. Only an Indian woman who has been a subject of this form of subjugation or observed it closely can be aware of the alarming nature of this custom. The narrator Tara, who has chosen the option of divorce and lives a free life, has acquired the position of a Situated Knower because she has lived in the traditional Indian society and experienced or known about the chains and problems faced by women closely even though she has chosen the path of freedom from the same. Tara tells the story of Tara Lata to contrast it with her own, since Tara Lata sacrificed her life for society while Tara rebelled to choose her own path. As a Situated Knower, Tara in Desirable Daughters defies tradition to find a new identity and be herself, instead of being what society wants her. Also, one of the daughters in the novel reflects, "How could we have allowed the instinct bred within us over the centuries to draw lines and never cross them, an infinity of lines, ever-smaller lines, and ever-sharper distinctions? I grieved for Didi's generation of "girls of good family," who put caste, duty and family reputation before self-indulgence" (Mukherjee, Desirable Daughters). This quote refers to the oppression of women in Indian society by killing their instincts, needs and wants in the name of family's reputation. This also accentuates the position of the three daughters as Situated Knowers .They had been in dominated situations, experienced oppression firsthand where the generation of the elder sister especially had to suffer to protect superficial ideals instead of following their hearts.

Bharati Mukherjee has raised a voice for depicting and documenting the plight of South Asian immigrants in America, more specifically, Indian Americans, filling a gap .A lot has been said about African American, Chinese, Hispanic and other immigrants but South Asian immigrants do not have an emphatic voice in literature. Bharati Mukherjee adds several dimensions to her stories by depicting the struggles of her female characters in India and America and how they emerge stronger from it. She takes Diaspora, feminism and other elements into account.

Further, Mukherjee lights a candle in relation to the cause of feminism by developing her characters in such a manner that they evolve from "feminine to female" (Myles 109). In addition, 
the female characters of Bharati Mukherjee fight the odds to acquire the status of victorious champions (Wong and Hasan 52). Further, Mukherjee's females have a conversion that is intuitive and at their core instead of their financial gain (Dodiya 309). Bharati Mukherjee comes from a culture in which her mother had to struggle because of having three daughters in a society favoring sons (Mukherjee and Edwards xii). This has also added weight to Mukherjee's place as a situated knower in the context of feminism.

Moreover, since Jasmine moves between husbands and her transition may seem to some as self-advancement and opportunism, showing novels of Bharati Mukherjee have received criticism as well. Another criticism may indicate that even though Mukherjee's stories are impactful, she may keep their scope limited because they seem to follow a similar blueprint. Mukherjee has been underlined to support American nationalism as well (Mishra 2). In some ways, America acts as a breather for her Indian characters despite the challenges they face here.

The past "space-time" is of prime significance in development of the characters of Mukherjee because this aspect is something that her characters have to run away from to reformulate and build their fresh identity (Shah 85). In brief, Mukherjee's work has enjoyed considerable popularity and critical acclaim but she has also received criticism and an example is Wife, which faced harsh criticism especially in the early times of its publication (Tandon 43).

\section{Conclusion}

The application of Situated Knowers and Standpoint theory helps to underline the issues faced by women in an informed manner because only women can go through and share what they have to face ,offering a credible testimony to the same. Bharati Mukherjee falls under the category of those writers that demonstrate women have a powerful presence and enjoy certain choices despite the harsh reality of their circumstances and challenges. The challenges that women face, especially in a foreign country like in Bharati Mukherjee's novels, can only be felt by women giving the characters in these novels and the writer herself the position of a Situated Knower. Tara in The Tiger's Daughter has to face disapproval from Indian society and even her mother because she has defied the norms. Also, an example of the oppression faced by women, as depicted in Mukherjee's novels and especially Wife, is evident from "My mother wants to call you Nandini, she does not like Dimple as a name" (Mukherjee, Wife). Dimple's husband has the audacity to tell her that his mother even wants to change her name. This underlines a root problem in Indian society where mother-in-law's sometimes have so much control over daughterin-law's that they can just reject their existence. Also, the daughters in Desirable Daughters are supposed to lead their existences based on society's demands and expectations entirely. In Jasmine, Jyoti also has to battle several adversaries because she is a woman and thinks about herself as "a fighter and adapter" (Mukherjee, Jasmine 40). Another example of how Mukherjee's characters exercise their rights, sustain their self-respect and dignity and rise above adversary is evident from how Dimple sticks to her original name and keeps it. On one hand, Wife shows Dimple breaking the annihilating chains of an oppressive marriage and on another hand, Jasmine demonstrates Jasmine cruising through life despite being subjugated, ridiculed, raped and defied. While The Tiger's Daughter shows Tara to carve her own path despite society's attempts to shape her identity. The novel Desirable Daughters demonstrates its protagonists to be themselves despite the society wanting to make their decisions for them. The characters of Bharati Mukherjee demonstrate a fresh form of feminism by articulating their feelings strongly and deviating from the norm to rise above oppression because Indian society and scholarly arena do 
not have clearly defined theories of feminism. Indian circumstances are different from Western ones, the feminist underpinnings and movements in Indian society are distinctive and different from those of Western society.

A gender-divided society works in such a manner that women experience different challenges, issues and obstacles than men and therefore, the disparity between Knowers underlined by feminist theory is a reality and stems from social configuration in a methodological manner. The benefits of the Situated Knower's and Standpoint theory to society stem from its prospective assistance in highlighting the issues and challenges faced by women by learning from their own account and experiences because only a woman knows her own and other women's struggles. Situated Knowers theory can help in making society better by sharing real issues faced by women and their consequences and finding solutions to problematic behaviors, norms and standards in society.

\section{References}

Alcoff, Linda and Elizabeth Potten(Ed.).( 1993). Feminist Epistemologies, New York:Routledge.

Babu, T. Ramesh, and A. Phaniraja Kumar. (2013).Feminist Perspectives in Bharathi Mukherjee's Novels. International Journal of Humanities and Social Science Invention. 2.3.

Clisby, Suzanne Holsworth, Julia. (2014). Gendering women: Identity and mental wellbeing through the life course.

Dodiya, Jaydipsinh. (2006).Perspectives on Indian English Fiction New Delhi: Sarup.

Dubey, Arjun and Shradha Srivastava. (2013).Social critique in Bharati Mukherjee's Jasmine International Journal of English and Literature.

Erten, Meltem U Bharati Mukherjee's. (2013). Jasmine: Cultural Conflict and Quest for Identity(Sosyal Bilimler Enstitüsü Dergisi.16.

Gardner, V, Catherine . (2009). The A to Z of Feminist Philosophy.Lanham, Md: Scarecrow Press.

Mishra, Vijay A. (1993). Critique of Bharati Mukherjee's Neo-nationalism SPAN: Journal of the South Pacific Association for Commonwealth Literature and Language Studies.

Mukherjee, Bharati, and Bradley C. Edwards. (2009).Conversations with Bharati Mukherjee. Jackson: University Press of Mississippi.

Mukherjee, Bharati. (2004).Desirable Daughters. New Delhi: Rupa. Co.

Mukherjee, Bharati. (1989). Jasmine. New York: Grove Weidenfeld.

Mukherjee, Bharati. (1972).The Tiger's Daughter. Boston: Houghton Mifflin company.

Mukherjee, Bharati. (1987).Wife. Harmondsworth, Middlesex, England: Penguin.

Myles, Anita. (2006).Feminism and the Post-Modern Indian Women Novelists in English.New Delhi: Sarup \& Sons.

O' Donohue, William T. (2013).Clinical Psychology and the Philosophy of Science. Cham: Springer.

Ramachandran, Bhuvana, and H. Madhava Bhat Bharati Mukherjee's Jasmine under the Lens of "Power Feminism International Journal of English Language, Literature and Humanities. 
Shah, Nandini. (2014). "Reconsidering Bharati Mukherjee: The Dissolution of Dialectics in Desirable Daughters." Research Journal of English Language and Literature (RJELAL). 85.

Srivastava, Swati. Feminist Approach in Two Writers: Bharati Mukherjee and Manju Kapur. (2014).IJRET: International Journal of Research in Engineering and Technology. 3.10.

Tandon, Sushma,Bharati Mukherjee's. (2004). Fiction: A Perspective. New Delhi: Sarup\& Sons.

Wong, Mitali P., and Zia Hasan. (2004). The Fiction of South Asians in North America and the

Caribbean: A Critical Study of English-Language Works since 1950. Jefferson: McFarland \& Company, Inc. 